\title{
LA CONCIENCIA JURÍDICA COMO UNO DE LOS ASPECTOS FILOSÓFICOS Y PSICOLÓGICOS DECISIVOS DEL DERECHO
}

\author{
LEGAL CONSCIENCE AS ONE OF THE DECISIVE PHILOSOPHICAL AND \\ PSYCHOLOGICAL ASPECTS OF LAW
}

\begin{abstract}
Pablo Jiménez Serrano
Doutor em Direito pela Faculdade de Direito da Universidade do Oriente, Cuba. Professor e pesquisador do Programa de Mestrado em Direito do Centro Universitário Salesiano de São Paulo- UNISAL. Professor do Centro Universitário de Volta Redonda - UniFOA. Professor do Centro Universitário de Barra Mansa - UBM. E-mail: metodologo2001@yahoo.com.br
\end{abstract}

Recebidoem: 06/03/2018

Aprovadoem: 19/08/2018

RESUMEN: En el presente artículo se discute el significado de la conciencia, su repercusión y materialización del Derecho contemporáneo. Se discute la conciencia como un aspecto decisivo para la eficacia del derecho, caracterizando la repercusión práctica de las denominaciones conciencia social, conciencia jurídica y conciencia moral para el mundo moderno. La investigación se desarrolla con base en estudios iusfilosóficos que procurando contribuir para la elaboración de modelos y políticas que posibiliten la edificación de la consciencia en niños y jóvenes, problema científico que presupone la relación y el diálogo entre la Educación, la Filosofía moral, la Psicología y el Derecho y cuya contribución teórica y práctica podrá contribuir para la resolución de los problemas sociales: jurídicos y morales presentes en las sociedades contemporáneas: criminalidad, inmoralidad, desobediencia social etc.

Palavras-Claves: Conciencia jurídica. Filosofía. Psicología. Derecho.

ABSTRACT: In the present article the meaning of consciousness is discussed, its repercussion and materialization of contemporary Law. The conscience is discussed as a decisive aspect for the effectiveness of the law, characterizing the practical repercussion of the denominations social conscience, legal conscience and moral conscience for the modern world. The research is developed based on iusophosophical studies that seek to contribute to the development of models and policies that enable the building of consciousness in children and young people, a scientific problem that presupposes the relationship and dialogue between Education, Moral Philosophy, Psychology and the Law and whose theoretical and practical contribution can contribute to the resolution of social problems: legal and moral present in contemporary societies: criminality, immorality, social disobedience.

Keywords: Legal awareness. Philosophy. Psychology. Straight.

SUMÁRIO:Introducción; 1 Conciencia y realidad; 2 Conciencia y actitud; 3 Conciencia social: jurídica y moral; 3.1 Conciencia jurídica; 3.2 Conciencia moral; 4 La anti-conciencia o crítico fenómeno del vacío "V"; Conclusión; Referencias. 


\section{INTRODUCCIÓN}

La filosofía de la conciencia está relacionada a cuestiones mucho interesantes que se albergan en las diversas áreas del saber humano, especialmente, en la Psicología, en la Sociología y en la Política. Los conceptos trabajados en esas áreas, por ejemplo, "mente", "identidad", "voluntad" y "emoción" dependen, en última instancia, de una única cuestión fundamental que aquí llamaremos de "problema de la correlación entre realidad, conciencia y conducta". Mas, ¿que es "conciencia"? ¿Cuál es su correlación con la "realidad" y con la "conducta"? Estas cuestiones que, a seguir, privilegiamos tienen una enorme importancia para nuestro estudio.

Para el entendimiento común tener consciencia, es tener conocimiento, noción, idea sobre alguna cosa. Conocimiento inmediato de su propia actividad psíquica o física. Se trata, así, del cuidado con que se ejecuta un trabajo se cumple un deber de responsabilidad, honradez, rectitud, probidad: ej. Hombre de conciencia.

En las filosofías clásica y moderna se considera la consciencia como un atributo altamente desarrollado en la especie humana: autoconsciencia. Facultad de hacer juicios morales de los actos realizados: ej. Conciencia recta, sabiduría práctica.

La sabiduría práctica, enseña Aristóteles (1992. Libro VI, cap. 7), es una virtud moral con implicaciones políticas. "Los individuos con sabiduría práctica son capaces de deliberar correctamente sobre lo que es bueno, no apenas para sí mismos, mas también para sus conciudadanos y para los seres humanos en general".

La "conciencia" parece ser un concepto complejo, ambiguo y de difícil significación. Se trata de una construcción lingüística ideal (no empírica, abstracta y no-espacial) que existe únicamente cuando la imaginamos, cuando la pensamos o definimos.

Se podrá, con efecto, dudar que el vocablo "Conciencia" sea un concepto jurídico o exclusivo de otras ciencias. En verdad, la palabra "Conciencia" (concientizar) es usada indistintamente en varios discursos jurídicos y dispositivos normativos. Así, por ejemplo, se afirma que el problema de la contaminación ambiental tiene su origen en la "conciencia ambiental" o que algunos órganos del Sistema Nacional de Defensa del Consumidor tienen como atribución la concientización del consumidor.

CDC: Art. 106. El Departamento Nacional de Defensa del Consumidor, de la Secretaría Nacional de Derecho Económico (MJ), el órgano federal que venga a substituirlo, es organismo de coordinación de la política del Sistema Nacional de Defensa del Consumidor, cabiéndole:

[...] (Traducción nuestra)

En el presente ensayo se discute la problemática del uso del concepto "conciencia" en las diversas áreas del saber humano. Importa destacar que, en la Teología, en la Ética y en la Psicología podemos encontrar significaciones específicas del término, siendo posible su estudio por medio del uso del método, histórico-sociológico. Ahora, en esas áreas del saber humano, se trabaja con inúmeras definiciones que acaban por tornar el concepto en estudio muchas veces vago, otras ambiguo.

La consciencia, en el área de la Psicología, es frecuentemente definida como una cualidad de la mente que abarca cualificaciones tales como subjetividad, auto-consciencia, sapiencia, y la capacidad de percibir a relación entre si un ambiente. El término acostumbra a ser clasificado de la siguiente manera: a) conciencia fenomenal (experiencia); b) conciencia de

\footnotetext{
1 Conciencia Ambiental y Desarrollo Sustentable. Disponible
} http://www.schwartzman.org.br/simon/ambiente.htm. Acceso el 6 de junio de 2011.

Revista de Direito Brasileira | São Paulo, SP | v. 20 | n. 8 | p. 4-18 |Mai./Ago. 2018 
acceso (procesamiento de las cosas que vivenciamos durante la experiencia). La conciencia se define como una cualidad psíquica, o sea, cualidad que pertenece a la esfera de la psiquis humana. Ella es un atributo del espíritu, de la mente, o del pensamiento humano.

Pues bien, el término conciencia no es unívoco, mas es usado con cierta frecuencia en los discursos políticos, en la literatura y en los estudios desarrollado en las áreas que se ocupan con la conducta humana. Así, como podemos conferir²

1. Conciencia como anticipación de la opinión de los otros, Henry Taylor (teólogo), TheStatesman, p. 63, publicado por Longman, 1836.

2. Conciencia como un cómplice, BenjaminDisraeli citado en "English men of letters", Volume 13. p. 148, John Morley, Editora Harper\&Brothers, 1894.

3. Conciencia de la propia ignorancia ya es un paso para el saber", p. 78, BenjaminDisraeli - Baudry.

4. Tomar conciencia para mudar la sociedad, $\underline{\text { ArnoldWesker. }}$

5. Conciencia bien-educada, $\underline{\text { Samuel Butler (1612-1680). }}$.

6. Conciencia es un juez que tiene un defecto frecuente en los jueces: adormece fácilmente". [Louis Legendre; Fuente: Chalita, Mansour.

7. Los más bellos pensamientos de todos los tempos. 4 Edición. Río de Janeiro: Assoc. Cultural Internac. Gibran. p. 86.

8. Conciencia individual del agente, Olavo de Carvajo.

9. Aconciencia nos torna más fuertes, Henri Poincaré en "El Valor de la Ciencia" (1904).

10. "Cuando las leyes son injustas, no tienen fuerza en el foro de la conciencia", $\underline{\text { Jaime }}$ Balmes; Fuente: "El Protestantismo".

11. "El heroísmo existe, existó y existirá para siempre en la conciencia de la humanidad", Thomas Carlyle.

12. Laconciencia de nación y de clase es una conciencia de especie, Leonardo Boff.

13. "La verdadera libertad es autoconsciente en la medida que yo tengo autoconsciencias alrededor", $\underline{\text { Hegel. }}$

14. "Quien quiere escuchar la voz sincera de la conciencia precisa hacer silencio en torno de si y dentro de si", Arturo Graf.

15. "La cultura histórica tiene el objetivo de mantener viva la conciencia que la sociedad humana tiene del propio pasado, o mejor, de su presente, o mejor, de si misma", Benedetto

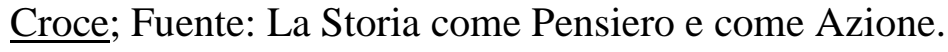

${ }^{2}$ Confiérase el uso (citación) del término en: http://pt.wikiquote.org/wiki/Consci\%C3\%AAncia. Acceso el 15 de enero del 2011. 
16. "La sabiduría ya existe en estado latente dentro de nuestra conciencia”, $\underline{\text { Buda. }}$

17. "Tenemos que ser crueles. Tenemos que recuperar la conciencia tranquila para ser crueles", Adolf Hitler.

Cícero.

18. "La adversidad la mayor consolación es la conciencia de las buenas acciones",

19. "Es una cuestión de formar una nueva conciencia del Estado que incluya a todos los ciudadanos productivos. Ya que los políticos del momento no quieren ni tiene como crear una tal situación, el socialismo sólo será conquistado con lucha", Joseph Goebbels; Fuente: "Die verfluchtenHakenkreuzler. Etwas zum Nachdenken" (1932).

20. "El hombre superior es impasible por naturaleza: poco le importa que lo elogien o censuren, él no oye sino la voz de la propia conciencia”, Napoleón Bonaparte.

21. "El hombre es el único ser en la naturaleza que tiene conciencia de que va a morir. Sabiendo que todo irá acabar, hagamos de la vida una lucha digna de un ser eterno", $\underline{\text { Paulo }}$ Coelho.

22. "Laconciencia es el mejor libro de moral que tenemos; y es, ciertamente, el que más debemos consultar", Blaise Pascal.

23. "Inteligencia espiritual es tener conciencia de que la vida es una grande pregunta en busca de una grande respuesta", Augusto Cury.

24. "El hombre libre es señor de su voluntad y solamente esclavo de su conciencia", Aristóteles.

25. "La mercancía es el núcleo económico del sistema capitalista y, en cuanto ella exista, sus efectos se harán sentir en la organización de la producción ye, consecuentemente, en la conciencia", Che Guevara.

26. "Hay en el fondo de las almas un precipicio innato de justicia y de virtud, con el cual juzgamos las acciones y la de los otros como buenas o malas; y es a este principio que doy el nombre de conciencia", Jean-Jacques Rousseau.

27. "Conciencia es una palabra usada por e los cobardes para meter miedo a los fuetes", William Shakespeare.

28. "La conciencia de que estamos todos bajo el juicio de Dios, junto con un cierto patrimonio moral y la observación de algunas normas que demuestran que la fe, para vivir, necesita expresiones comunes, algo que perdemos en cierta medida", Papa Bento XVI en entrevista al periódico "La República" en 2004.

29. "Si hube holocausto del pueblo judío hace apenas 60 años, hoy se trata de impedir el holocausto de decenas de pueblos amenazados de ser atacados e, incluso, exterminados, ya que, según se anuncia, todas las armas pueden ser utilizadas para atacar, preventivamente y de sorpresa, en cualquier obscuro rincón del planeta. El denominado mundo occidental y cristiano debería tomar conciencia de esa realidad, antes de que sea demasiado tarde, como parece que está 
ocurriendo, delante del gigantesco holocausto provocado por la pobreza, por el hambre, el subdesarrollo, la falta de Educación y de salud, la globalización neoliberal y el actual orden económico y social impuesta a la humanidad, que, a cada año, matan a decenas de millones de personas, en los países del Tercer Mundo", Fidel Castro.

30. Tenga una buena conciencia, para que, en aquello donde se habla mal de usted, se queden confundidos [...]. Pedro 3:16].

Se observa igualmente que, en la literatura moderna, existen conceptos correlatos tales como, autoconciencia y autoconocimiento, reflexión etc. y se afirma que la autoconciencia es el elemento fundamental de la conciencia, pues sin ella no hay conciencia ni reflexión sobre la conciencia. Debido a su especificidad y utilidad, tales definiciones no serán objeto de la presente etapa de investigación.

Con Arthur Schopeñauer (2007, p. 88 -90), por ejemplo, aprendemos que "honra es la conciencia externa y conciencia es la honra interna". De acuerdo como enseña el citado autor es solamente en sociedad que las capacidades de un hombre pueden ser llamadas a la plena actividad. Él luego descubre eso cuando su conciencia comienza a desarrollarse y surge en él el deseo de ser visto como un miembro útil a la sociedad, como aquel, por así decir, que es capaz de tener su papel como hombre. La honra cívica para Schopeñauer tiene la esfera más amplia de todas. Consiste en la suposición de que tendremos respeto incondicional por los derechos de los otros y, por tanto, nunca usaremos medios injustos o ilegales de conseguir lo que queremos. Es la condición de todos los intercursos pacíficos entre hombre y hombre. La honra cívica se aplica igualmente a todos, sin excepción de clases.

Más allá de la significación, ciertamente, las causas del actual estado de conciencia o la falta de conciencia, no siempre fue objeto de preocupación o de estudios por parte de los juristas e investigadores históricos ni modernos.

Evidentemente el concepto "conciencia" no es exclusivo del Derecho, por tanto, es conveniente trabajar con una definición operacional específica. Así, a los efectos del presente estudio, definimos la conciencia como el "Bien-interior", un estado espiritual que domina y define sentimientos, emociones, convicciones y actitudes, una condición que decide la resolución de dilemas morales.

Por tanto, la conciencia es el eslabón que conecta el mundo del ser al mundo del deber ser y su edificación presupone un modelo jurídico-educacional que permita la "internalización" de los valores, esto es, del sentido de las normas morales y jurídicas. De esta manera, la conciencia puede ser edificada y reorientada con el auxilio de esos recursos.

Otra observación, no menos importante, es la de que la ciencia (el conocimiento) auxilia en la edificación de la conciencia. En ese punto, juzgamos conveniente observar que el conocimiento influye, mas no determina la edificación de la conciencia: personas tituladas no son necesariamente conscientes. Delincuentes y corruptos siempre afirman ser honestos. Así, por ejemplo, La Ética Pública: la moralidad administrativa, la Ética Profesional, la Ética Empresarial, la Ética Médica etc. colocan en debate que la inmoralidad y la corrupción son propias de hombres titulados: empresarios, políticos, jueces, médicos, promotores, profesores etc.

\section{CONCIENCIA Y REALIDAD}

Si existe, verdaderamente, una conexión entre la conciencia y la realidad, también existe una correlación entre la conciencia y la conducta, tales son conceptos diferentes, mas dialécticamente relacionados.

Observamos que la "realidad" y la "conciencia" existen en una relación dialéctica. En conformidad con ese punto, la "consciencia" y la "conducta" se integran en una relación causal: 
causalismos moral y jurídico. Personas no nacen éticas ni jurídicamente preparadas para interactuar en el mundo, mas, con frecuencia, exigimos de ellas una conducta moral pautada por normas socialmente convencionadas.

En la visión de Alf Ros es improbable que el ser humano tenga una conciencia innata de cuáles son los objetos adecuados a la satisfacción de una determinada necesidad. El deseo es originariamente ciego, un esfuerzo desprovisto de meta. Un bebé está intranquilo y llora porque necesita de alguna cosa: alimento, pañales limpios, ser calentado o refrescado. Entretanto, sus impulsos no tienen una dirección particular y no hay razón para suponer que un bebé tenga alguna idea de lo que necesita (y de lo que es bueno o correcto). Gracias a la ayuda de otros seres humanos, sus diversas necesidades son satisfechas y en la medida que su conciencia aumenta gradualmente, mejora su capacidad para reconocer los diversos seres capaces de satisfacer su voluntad que en situaciones distintas les fueron ofrecidos. Así, las experiencias del individuo al respecto de lo que es; lo que satisface sus necesidades hacen con que su deseo no sea más ciego y transforman su acción impulsiva, sin dirección, en un esfuerzo orientado por un propósito, que busca un fin específico. (ROSS, 2000, p. 410)

Por ese motivo, no nos parece correcto calificar la conducta de un incapaz de inmoral o ilegal, mas si de una inconciencia propensa a la inmoralidad y a la ilegalidad. El adolecente que mancha la pintura de una casa es más propenso a la ilegalidad, el joven que practica actos de violencia es más propenso a la criminalidad.

Es en la convivencia, esto es, en la convivencia familiar, escuela, en la iglesia, etc. que el ser humano se desarrolla. Jóvenes absorben las reglas (de comportamiento: morales, jurídicas, de juego, de etiqueta, etc.) en esa convivencia social condicionada por normas y conceptos éticojurídicos. Entonces, la conciencia (el Bien-interior del cual hablamos) se edifica en la realidad y en la convivencia social, en la medida en que seamos capaces de inhibir tal propensión en la propia convivencia social.

En verdad, los conceptos cambian con el tiempo, pero lo que no cambia es la condición de ser humano. Es que todo hombre es un ser social y, por tanto, siente la necesidad de vivir en "sociedad" (WILLIAMS, 2005 p. 33). Vemos, así, la sociedad como una unidad cultural, en parte identificada por sus valores. Una dada práctica o creencia está mucho más ligada a la estructura de una sociedad de lo que puede parecer a primera vista (convivencia social). La convivencia social, por tanto, presupone la existencia de reglas. Debemos, pues, considerar que "no puede haber sociedad sin reglas morales" (WILLIAMS, 2005 p. 6). Luego, la ética (y también el Derecho) se hacen presentes y son necesarias en toda y cualquier sociedad, pues ella tiene como objeto la convivencia humana (convivencia social).

Con efecto, el ser humano se conduce influenciado por un "juego de intereses y necesidades". Es, con base en ese juego, que el hombre piensa, se proyecta, prescribe y asume actitudes ante determinados problemas, dando mayor valor a lo que considera ser momentáneamente un beneficio. Esta es una interpretación diferente de las ya conocidas concepciones subjetivista, relativista, y utilitarista, para la cual consideramos correcto sumar la necesidad de un "justo equilibrio moral", aspecto que merece un espacio en el mapa de la ética pública. (WILLIAMS, 2005 p. 19-20, 24, 31-36, 137-138)

$\mathrm{Si}$, por un lado, la conciencia se edifica en la realidad (convivencia); por otro, los eventos vivenciados en esa realidad se traducen en experiencias capaces de provocar sensaciones que inciden en la conducta, traduciendo la voluntad en actitudes (acción). Importa, por ejemplo, saber que, en ese proceso, la conciencia funciona como un catalizador de la acción. Así, conforme a la riqueza o a la pobreza de nuestro Bien-interior (conciencia) estaremos convencidos de que nuestra actitud es normal y correcta. "Fundamentalmente, porque somos también racionales, atentos a las contradicciones, es que podemos tomar conciencia de nuestros aspectos irracionales". (PIAGET, 1994, p. 13) 
Al respecto de esta discusión, existe un problema teórico que consiste en determinar cómo podemos evaluar y medir la conexión entre la conciencia y la acción (conducta). Vimos que la "conciencia" no es un concepto concreto que puede ser tocado, pesado o medido. La conciencia no es vista, no existe en el plano empírico, mas solamente por las actitudes reiteradas es que podemos evaluar o medir su nivel, observando el confronto conciencia versus anticonsciencia.

En ese sentido, la evaluación propuesta en el presente estudio es de tipo comportamental, esto es, se desarrolla con base en la observación de las actitudes y decisiones tomadas durante la resolución de dilemas morales, esto es, de los conflictos internos que generan las decisiones cotidianas. Se trata de medir lo que es hecho, esto es, cual es la actitud tomada ante determinada situación y de evaluar se tal actitud es repetitiva (o habitual). Así, por ejemplo, la agresión física o moral, el uso de drogas e innúmeros otros actos que originan conflictos intersubjetivos, cuya solución navega en el plano de la conciencia. Personas deben y pueden estar preparadas para una "evaluación razonable" de sus actos conforme a las reglas morales y jurídicas vigentes.

Decimos entonces que la única alternativa posible para edificar la conciencia es la evaluación de los actos (conducta). Es consciente quien practica actos conscientes, nos tornamos éticos practicando actos éticos.

Importa, entonces, una metodología (la idealización de un modelo) que nos permita edificar la consciencia en aras de la convivencia, para a orientación do comportamiento y no solamente para la predicción y el control, como pretende la Psicología.

\section{CONCIENCIA Y ACTITUD}

Personas "conscientes" de sus actos subordinan sus intereses e necesidades (deseos, y satisfacción) al ideal de un objetivo (la convivencia social).

Estudiosos del asunto, con frecuencia, establecen una distinción entre las necesidades corporales y espirituales. Al primer grupo pertenecen, por ejemplo, la necesidad de respirar, de abrigo, de agua y de alimentos, de excreción, de higiene, de actividad sexual y de descanso. El segundo grupo incluye la necesidad de estímulo o distracción, de expresión, de producción, de compañía, de amor o cuidado, de seguridad, la necesidad de poseer, de ayudar; también la necesidad de destrucción, de autoafirmación, de auto-respeto, de justificación, de conocimiento de harmonía etc. Los intereses no son necesariamente egoístas (intereses propios). Los intereses basados en la necesidad de ayudar son dirigidos a la satisfacción de necesidades ajenas. Nace de un impulso de ayudar a los otros que están necesitados y se funda en sentimientos de simpatía en relación a ellos. (ROSS, 2000, p. 410-411)

Conforme enseña Alf Ros (2000, 411), los intereses son experimentados por personas, no conocemos otros centros de experiencia y, en ese sentido, son individuales, hablar de intereses colectivos o comunitarios, en el sentido de que es el grupo o la comunidad que experimenta el interés, carece de sentido. Debemos procurar otra forma de atribuir a esas palabras un significado aceptable.

La anterior afirmación no es del todo feliz, pues, en verdad, pueden existir, concomitantemente, intereses ( $\mathrm{y}$ necesidades) individuales $\mathrm{y}$, también, colectivos. Vemos al siguiente caso.

Imaginemos tres individuos, $\mathrm{A}, \mathrm{B}$ y $\mathrm{C}$ viviendo en el mismo grupo habitacional. Todos ellos quieren paz y seguridad. Los tres tienen el mismo interés y la misma necesidad en proteger sus bienes y familias, por tanto, podemos afirmar que sus intereses coinciden. Supongamos, igualmente, que la seguridad colectiva requiere del pagamento de una cuantía anual como forma de cooperación (contribución). Cada uno de ellos, entonces, tiene la obligación solidaria de cooperar, caso contrario la empresa especializada en seguridad no prestará el servicio. Así, 
podemos afirmar que sus intereses están conectados a una obligación común. Finalmente, podemos decir que cada uno siente la necesidad de cooperar para llegar a un objetivo común. Es en ese sentido que hablamos en conciencia social, y por extensión, en conciencia jurídica y moral, cuando, por ejemplo, tenemos el interés y sentimos la necesidad de pagar los tributos, de respetar la propiedad ajena, de no agredir la naturaleza, de administrar bien la cosa pública, etc.

Queda claro que, la coincidencia de intereses, depende también de circunstancias internas y externas. En ese caso, se percibe una situación factual necesaria (circunstancia externa) que origina un sentimiento de solidaridad (circunstancia interna), que mueve a los individuos en la misma dirección, orientación necesaria para la satisfacción de intereses comunes. Por tanto, es preciso que los sujetos tomen ciencia de tales intereses y necesidades, esto depende de un conocimiento racional del estado actual de solidaridad. (ROSS, 2000, 412)

Es obvio que el sentimiento de solidaridad origina actitudes individuales que satisfacen un objetivo común, logrado a partir de la concientización acerca, por ejemplo, de la importancia de la paz, del desarrollo socioeconómico, de la responsabilidad socio- ambiental, para todo ser humano.

Que los intereses individuales y coincidentes sean experimentados también como intereses comunes, depende de algo subjetivo (conciencia), por ejemplo, que cada una de las partes se identifique de tal manera con las otras o con todos, que nazca en cada una de ellas una "conciencia de grupo". Significa, entonces, que cada una se sienta como si no estuviera actuando en su propio nombre y en su propio interés, mas como un órgano, de una comunidad. (ROSS, 2000)

Ha de notarse que los intereses individuales, de alguna manera, se vinculan a los sociales. Los derechos individuales encuentran sus límites en los derechos sociales. La propiedad y la posesión de bienes, así, se pueden chocar con los intereses colectivos.

Esos intereses son coincidentes y están relacionados en un sólo aspecto: todos estamos interesados en que haya un ordenamiento general de la propiedad que garantice, a cada uno, la seguridad. Este es un interés social, coincidente dentro de un grupo para el cual existe un cierto orden social. (ROSS, 2000, 414)

\section{CONCIENCIA SOCIAL: JURÍDICA Y MORAL}

Vimos que la convivencia humana (convivencia social condicionada) alberga, concomitantemente, intereses (y necesidades) individuales y colectivos. Así, afirmamos que, solamente por medio de una conciencia colectiva (o social) seremos capaces de llegar a objetivos comunes: vida, seguridad, paz, orden económico, desarrollo, etc.

Con base en una comprensión sociológica, la conciencia colectiva podría ser considerada como siendo un conjunto de representaciones, de sentimientos o de tendencias no explicables por la Psicología del individuo, mas por la visión de objetivos (fines o finalidades) trazados por la propia sociedad. En este sentido, una persona consciente procura separar lo que es bueno para él de lo que es útil para todos.

En este punto, consideramos conveniente destacar los enseñamientos de Aristóteles (ARISTÓTELES, 1992 p. 11, 17, 18, 20 - 23), conforme el citado autor, las acciones buenas y justas parecen ser variadas y vagas, al punto de ser considerada su existencia apenas convencional, y no natural (bien común - bien universal). Bajo este prisma, la felicidad también puede ser difundida: infundiendo cierto carácter en los ciudadanos, tornarlos buenos y capaces de practicar buenas acciones (responsabilidad - conciencia social). El hombre es un animal social, y la felicidad de cada criatura humana presupone, por esto, la felicidad da su familia, de sus amigos y de sus conciudadanos, la manera de asegurar la felicidad de las criaturas humanas es proporcionar un buen gobierno a su ciudad; se debe determinar, entonces, cual es la mejor forma de gobierno. Nos tornamos justos practicando actos justos, moderados, viviendo moderadamente. 
Según el punto de vista aristotélico, podemos inferir que la conciencia, de la cual aquí nos ocupamos, también puede ser difundida: edificando cierto carácter en los ciudadanos, tornándolos buenos y capaces de practicar buenas acciones, procurando propiciar el bienestar de las familias, de los amigos, de los conciudadanos, etc. Vemos aquí la conciencia social como condición del bienestar social.

La conciencia nos habilita a distinguir el bien del mal, y de ella resulta el sentimiento del deber, de la responsabilidad y la necesidad de practicar actos justos, y la reprobación o el remordimiento por no haberlos practicado.

El factor decisivo en la resolución de un dilema moral concreto podrá ser el grado de conciencia individual y social del agente. La verdad es que la conciencia social se expresa como una capacidad interior del ser humano, esto es, una "capacidad de acción libre y autónoma del individuo. Significa, encima de todo, la capacidad de resistencia que el individuo tiene frente a las externas presiones provenientes del medio (inclusive presiones morales ilegítimas)". (BITTAR, 2009, p. 33)

Así, pensamos que la moral: valores, normas, virtudes pueden ser internalizada por medio de un proceso de edificación de la conciencia en niños y adolescentes. Igualmente, por medio de un proceso de educación inclusiva e integrada, esos valores pueden ser difundidos en la sociedad.

\subsection{Conciencia jurídica}

Anteriormente significamos la conciencia como un "Bien-interior", esto es, como un estado espiritual que domina y define sentimientos, emociones, convicciones y actitudes, condición decisiva para las decisiones y resoluciones de dilemas morales. Nos resta, ahora, tratar la conciencia en sus dos posibles sentidos, a saber, jurídico y moral.

Consideramos el sentido jurídico de la conciencia (conciencia jurídica), como siendo aquella parte del "Bien-interior" que opera como un catalizador de la conducta, y que nos orienta en la aprobación o reprobación de un acto o situación social, al tener como referencia una norma jurídica.

Decimos, entonces, que el sentido jurídico de la conciencia muchas veces coincide, mas otra difiere del sentido moral. Esa distinción se funda en la idea de que la conciencia jurídica se edifica a partir de un orden jurídico preestablecido, esto es, con base en un conjunto de normas válidas y vigentes en una determinada sociedad. Hablamos de un orden normativo que se sabe coercitivamente, mas también educativo y que incluye deberes y sanciones evidentes expresadas en forma de normas primarias y secundarias.

Luego, el destinatario de la norma observa lo que, jurídicamente, se torna obligatorio, evitando la sanción (externa) definida por el legislador. Así, por ejemplo, la violencia es jurídicamente punida, pues está tipificada en la norma. Practicar o no practicar un acto violento es un dilema de conciencia que jurídicamente se resuelve por medio del conocimiento e internacionalización de las razones del derecho positivado.

Si los infractores de la ley deben ser punidos en relación a su culpabilidad es porque conscientemente infringen la ley. Luego, lo que no está prohibido debe ser permitido. Y aquí nos permitimos preguntar: si es correcto legalizar el consumo de drogas, si debemos permitir la prostitución, etc. Estas y otras son cuestiones de conciencia jurídica y, concomitantemente, de conciencia moral. En cierta medida, afirma Ross (2000, p. 421), la conciencia jurídica es determinada por el propio ordenamiento jurídico existente $\mathrm{y}$, al mismo tiempo, ella ejerce influencia sobre este último.

Existe, entonces, una correlación (diálogo) entre el derecho y la conciencia. En verdad, el derecho, como conjunto de normas (ordenamiento) es un producto humano y sistemático que 
emana de la conciencia social y para ella se vuelve. Como resultado de esa dialecticidad, las relaciones jurídicas expresan un nivel de desarrollo superior en cada período histórico.

Es posible, con efecto, afirmar que las normas jurídicas tienen sentido de vigencia y de eficacia social cuando son acatadas por la conciencia jurídica popular. El derecho es aplicado porque es vigente y eficaz (eficacia social) cuando respetado u obedecido por los destinatarios. En ese sentido, la conciencia jurídica es vista como un concepto perteneciente y necesario de la convivencia social, estando el derecho al servicio de ella. Se procura, de esta forma, reducir al ámbito individual de las opiniones subjetivas, emparejado con el plano moral, bloqueando, de ese modo, el entendimiento del derecho como una orden nacional esto es, como fenómeno intersubjetivo. (ROSS, 2000, p. 13)

Es por medio de la conciencia jurídica que el ciudadano se somete a un dado orden jurídico legítimo. Luego, la consciencia jurídica es una denominación propia derivada de la función del derecho y para el derecho. No habrá derecho eficaz sin conciencia (respeto y obediencia).

Se puede, con efecto, afirmar que la conciencia jurídica orienta el respeto, involuntario y desinteresado, al conjunto de reglas externas conocidas. Se trata de un sentimiento que define la conducta, distinguiendo el bien del mal, sentimiento del deber ante un poder que se sabe legítimo y prescrito por la moral y el derecho. Y tal es la finalidad de estas dos áreas, buscar una conciencia común que permita el reconocimiento, el amor y el respeto entre las personas. (HABERMAS, 2001)

En síntesis: la obediencia (o conciencia jurídica) no se edifica recrudeciendo el carácter coercitivo de las normas, entonces con la introducción de nuevas formas de internalizar valores, por medio de modelos jurídicos y educacionales. La edificación de la conciencia jurídica es consecuencia de la internalización de valores morales y principios jurídicos de forma a que, ante un dilema, el ciudadano observe y respete la norma por fuerza de su probidad.

\subsection{Conciencia moral}

Como afirma Ricardo Salas Astraín (2008) la cuestión de la conciencia moral es fundamental para el análisis ético-religioso de los actos humanos, buenos o malos, pues, de hecho, se insiste en el carácter autoconsciente del sujeto que los practica. Particularmente, en la filosofía griega, se refiere a la capacidad para discernir y reconocer concretamente los actos buenos o malos, relativos a la acción (phronesis). Para Descartes y Spinoza, la conciencia está vinculada a la tristeza o al remordimiento (remords de conscience) al realizar algo incorrecto. Ya entre los alemanes se entiende como la facultad que juzga la moralidad de nuestras acciones. Se trata, así, de una categoría ética y moral que coloca a la conciencia moral delante del sentido mismo de las cuestiones prácticas, por ejemplo, de modo a cometer aciertos y no errores. La exigencia autónoma de hacer el bien que torna morales ciertos actos, y que, por extensión puede ampliarse a las acciones políticas y jurídicas, se contrapone a un hacer el mal a cometer errores, y que puede incidir en una deformación de la misma conciencia. Así, la conciencia moral tiene cierta ambivalencia y se vincula a otras formas da conciencia, que en su dimensión general puede ser psicológica, epistemológica y metafísica. La conciencia moral parece tener un carácter inherente al ser humano, de modo que con frecuencia la discusión objetiva, por ejemplo, si su origen es natural o social. En los debates modernos originados acerca de la defensa de los Derechos Humanos, esta categoría volvió a ser considerada relevante, pues ayuda en la conceptualización de la problemática de la debida formación de la conciencia de los profesionales, lo que significa entender el valor de una "decisión consciente" de cara a la defensa de los derechos. 
El termino conciencia, en su sentido moral, encierra la capacidad de desarrollar un juicio distinguiendo el cierto de lo errado. Así, la conciencia moral se traduce en un sentimiento de honestidad que orienta el respeto a la moral predominante.

Un juicio moral, en principio, abarca valores y normas morales. Diferentemente de la conciencia jurídica, la conciencia moral implica una sanción interna, medida por el sentimiento de remordimientos, cuando los valores morales son violados. En consonancia con eso, Alf Ross (2000, p. 417-418) afirma que las actitudes morales tienen origen social, son inculcadas en la persona por la persuasión sugestiva de su medio. La peculiaridad de la persuasión que crea la moralidad y que acontece en los primeros años de vida. Desde la infancia, el niño crece en un medio social, representado, primero por los padres, hermanos y hermanas, mas tarde por e los colegas de la escuela y los profesores. En ese medio el niño es constantemente sometido a un bombardeo de persuasiones constante con la tradición cultural común del grupo social, con la herencia social. Las persuasiones consisten, primeramente, en exhortaciones verbales: " $\mathrm{No}$ mientas!”, “¡Mantenga su palabra!”, “¡No jures!”, “¡No seas egoísta!”, “¡Es cobardía maltratar a alguien menor que tú!". Estas exhortaciones son luego apoyadas por otros medios de persuasión que expresan aprobación y reprobación: elogio, censura, castigo, aislamiento del grupo, privación de afecto y simpatía, etc. De esa manera, el niño crece en el interior de una amplia red de reglas convencionales que abarcan los aspectos más variados de la vida: reglas del lenguaje, de juego, de intercambio social, de urbanidad y de moralidad en sentido estricto. Estas reglas son sentidas como morales, esto es, obligatorias en la medida en que son susceptibles de chocarse con el placer y las inclinaciones personales.

De acuerdo con el citado autor, por ejemplo, las reglas de la gramática son experimentadas como puramente convencionales, en cuanto el imperativo de no jurar adquiere un tono moral. Las exigencias de higiene y de urbanidad son experimentadas originalmente por el niño como exigencias morales, mas poco a poco la conducta correspondiente es inculcada hasta alcanzar un grado tal de automatismo que ya no se desea actuar de manera distinta. Las reglas pierden así su carácter moral.Con el tempo, continúa el citado autor, el factor de sugestión (amonestación de los padres) puede desaparecer. La actitud moral será, entonces, acoplada directamente a la situación y a la regla moral correspondiente. El adulto, o el adolescente no recuerdan como los impulsos morales fueron en él implantados. A pesar de eso, vive estos impulsos plena y espontáneamente como una fuerza que reprime sus inclinaciones. Esa circunstancia demuestra la inexplicabilidad que caracteriza la moral. En cuanto parece bastante natural satisfacer nuestras necesidades hay algo extraño en el hecho de que cumplimos nuestro deber incluso contra nuestros intereses. No parece que el deber pueda ser atribuido a la nuestra naturaleza. Parece obvio, consecuentemente, interpretar el impulso moral como expresión de una específica validad sobrenatural que tiene su fuente en Dios o en la naturaleza racional, suprasensible, del ser humano, que nos habla por medio de nuestra conciencia. (ROSS, 2000, p. 418)

\section{LA ANTI-CONCIENCIA O CRÍTICO FENÓMENO DEL VACÍO "V"}

La anti-conciencia o crítico fenómeno del Vacío "V" alcanza su dimensión social cuando la conducta del agente agrede los intereses grupales o sociales, contrariando la moral y el derecho. La creencia de que determinada conducta es correcta, por ser ventajosa para el agente, sin importarse con el daño o el dolor de otro es propia de la anti-conciencia.

Estar en un estado de tipo "V" significa estar propenso a cometer actos antisociales: ilícitos e inmorales. El estado de tipo "V" es el estado en que gobiernan (dominan) los intereses que, conforme explica Alf Ros, en sentido amplio, abarca todo el estado de conciencia que encierra una actitud. En este sentido, el ser humano aquí es guiado por intereses individuales, revelando el interés por todo aquello acerca de lo que experimenta y define su actitud considerada 
positiva para él, pero que puede ser considerada negativa para los otros. Con la palabra interés se designa una clase particular de actitud conocida en la Psicología como actitudes fundadas en necesidades. (ROSS, 2000, p. 410)

El acto o la conducta calificada de inmoral o de ilegal es vista como normal por parte del sujeto en este estado "V". Así, por ejemplo, el relacionamiento extraconyugal y el lucro no ético son considerados normales. No mirar el examen del otro alumno (durante el período de prueba), no mentir, etc. son cosas del pasado.

Se trata, pues, de un vacío moral donde las normas no existen, o no son reconocidas como necesarias. Tal desorientación inhibe el reconocimiento de lo que es contrario a la moral y al derecho.

El vacío obscurece el pensamiento. En ese estado es imposible distinguir lo que está correcto de lo incorrecto. Sólo una ilustración práctica nos ayudaría a comprender los niveles de conciencia y, consecuentemente, el estado de inconciencia. Imaginemos un individuo que, por mero estado de necesidad, abre violentamente la puerta de un vehículo ajeno para tratar de salvar a un niño. Imaginemos, igualmente, el mismo individuo en idéntica situación, mas ahora la intención sería robar una bolsa, acto que posteriormente lamenta y se arrepiente. Imaginemos, ahora, a este sujeto violentando con frecuencia carros, robando bolsas y amenazando a las personas. Vemos, pues, que el "V" es definido por la violación consciente de un conjunto de valores morales y de normas jurídicas.

Agentes (niños, adolescentes y adultos) muchas veces comenten errores y no reconocen que su conducta está incorrecta. Personas, con frecuencia, se muestran dispuestas a errar y a no corregir sus errores, porque está convicta de que su conducta no tiene la menor importancia en el plano social. Algunas personas están dispuestas a agredir, a robar, a usar drogas, etc. a menos que algo se lo impida, pues, precisan de reglas, precisan de normas. En esos casos estaremos evaluando problemas de anti- conciencia, esto es, de crítico fenómeno del vacío ("V").

Conforme los niveles del vacío "V", las personas procurando atingir un interés o satisfacer una necesidad, generalmente individual y no colectiva. Así, procuramos entender las razones de las diversas interpretaciones y responder al problema de la diversidad de actitudes. Para mejor entender las diferencias existentes entre los niveles del vacío, proponemos el análisis del siguiente cuadro-modelo. Veamos.

Cuadro n. 1- Niveles representativos de la anti-conciencia.

\begin{tabular}{|c|c|c|}
\hline NIVELES & TIPOLOGÍA & CARACTERÍSTICAS \\
\hline Primer Nivel & Primitivo & $\begin{array}{c}\text { De desorientación por el } \\
\text { "desconocimiento": } \\
\text { desobediencia inconsciente }\end{array}$ \\
\hline Segundo Nivel & Intermediario & $\begin{array}{c}\text { Desorientación por la } \\
\text { "creencia": desobediencia } \\
\text { semi-inconsciente }\end{array}$ \\
\hline Tercer Nivel & Avanzado & $\begin{array}{c}\text { Desorientación por la } \\
\text { "convicción": desobediencia } \\
\text { consciente }\end{array}$ \\
\hline
\end{tabular}




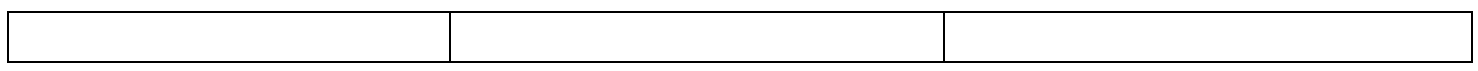

En el primer nivel se destaca la desorientación por la ausencia de información (“desconocimiento") de las normas, sus razones y consecuencias sociales. Los niños, adolescentes y adultos muchas veces se conducen sin medir las consecuencias de sus actos, generalmente por desconocer la razón o la importancia de una conducta contraria a la moral y al derecho (desconocimiento). Ejemplos: a) un niño de 5 años usa el arma del padre para jugar con el amigo; b) adolecentes y, también, adultos que, por desconocer de las prescripciones legales, cometen actos ilícitos.

En el segundo nivel, una vaga "creencia" acerca de la aceptación social de una acción lleva al agente al error. En este nivel "es evidente la conexión entre una creencia o el deseo y el comportamiento que usualmente los acompaña". (LYCAN, 2002, p. 169)

Así, por ejemplo, la creencia en la impunidad y en la aparente libertad garantizada por las leyes y por la ineficiencia del Estado lleva al adolescente y al adulto a practicar actos que exceden los límites de las normas morales y jurídicas.

En el tercer nivel predomina la "convicción" de que la acción es ventajosa para una persona o grupo, en detrimento de los demás, así, como, a seguir, ejemplificamos:

$1 \mathrm{El}$ abogado pode peticionar contra su cliente.

2 El empresario que, procurando lucro, no respeta los derechos de sus trabajadores.

3 El político que usa los recursos públicos para satisfacer sus intereses personales.

Creencia y convicción son dos constructos diferentes. Podemos creer que las actitudes de un grupo son normales y correctas, por causa de la edad. Así, por ejemplo, la práctica del bullying y el acto de colocar fuego en un mendigo pueden parecer actos divertidos para un grupo de agresores. Ya la convicción ultrapasa la creencia, por ejemplo, un criminoso puede considerar que matar a alguien es un acto de venganza natural y necesario, un abogado puede concluir que su profesión justifica la "in verdad" o que alguien puede considerar normal el acto doloso que mira al placer y a la felicidad, etc.

La objeción de conciencia no es, por tanto, como a veces se ha definido, "la negación de la prestación de servicio militar por motivos de conciencia o en razón de una convicción profunda de orden religiosa, ética, moral, humanitario, filosófica u otra de igual naturaleza. Es la negativa a realizar cualquier prestación o actividad, contra las propias creencias". (GONZÁLEZ, 1995, p. 38)

Imaginemos la siguiente situación: Pedro, actualmente con 11 años de edad, está con un grupo de amigos. Roberto, de 19 años, decide manchar la pared de una casa. Pedro, para no ser excluido del grupo, también participa. Pedro, aquí, enfrenta un dilema de conciencia.

En el caso anterior, evidentemente, la actitud de Pedro enfrenta un deber moral, tal vez conocido, por un lado, mas, por otro, predominan los intereses de no ser excluido del grupo. La actitud interesada frente a una orden social, enseña Ross (ROSS, 2000, p. 419), es una actitud derivada y condicionada por la creencia de que la regla o la orden puede satisfacer ciertas necesidades.

El punto de vista fundado en el interés está, pues, condicionado a ciertas creencias y, en tal medida, puede ser justificado por argumentación racional. La actitud moral, al contrario, es una actitud directa y absoluta frente a una norma de acción o de orden social. Es irracional el sentido de que expresa una emoción y es inaccesible a la justificación y a la argumentación. La fuerza motivadora de esos tipos de actitudes varia de una persona para otra, segundo ciertas 
creencias condicionantes sobre la naturaleza y el origen de la condición moral. De esta forma, el autor distingue dos tipos principales: la actitud moral dogmática y la actitud moral ética.

La interpretación semántica de las creencias es vagamente determinada por diversos factores contextuales. Algunas interpretaciones son correctas, ya otras son pura y simplemente incorrectas, y ese es el hecho del sujeto creer en una cosa y no en otra. Algunas características causal-históricas y teleológicas complejas del ambiente del sujeto tornase objetivamente verdadero que el sujeto crea en tal y cual cosa y no en tal o cual otra, sea o no esa característica interesante o científicamente bien-comportada. (LYCAN, 2002, p. 190)

De cualquier forma, los tres indicadores: desconocimiento, creencia y convicción inciden sobre el papel comportamental del sujeto. Así, estar en un estado "V" implica estar prestos a la inmoralidad y a la ilegalidad por cualquiera de esos factores.

Agentes: niños, adolescentes, empresarios, políticos, profesionales liberales, etc. en la actual sociedad de consumo, disfrutan de una libertad de voluntad sin preocuparse con su responsabilidad moral. Luego, son alarmantes las consecuencias morales y jurídicas del estado "V" en una sociedad que se sabe en crisis moral.

Así, la eficacia social de las normas depende de su obediencia (acatamiento). La desobediencia, inconsciente, semi-inconsciente o consciente torna inútil el derecho y la ética. La violencia en las escuelas, el aumento de la criminalidad, de la corrupción, de la informalidad, etc. es consecuencias del "V". Niños que hoy son violentos y desobedientes se tornarán criminosos y corruptos. Recordemos que los niños de hoy son los futuros profesionales, obreros, políticos, médicos, profesores, abogados, promotores, jueces, etc.

Concluimos, entonces, que el "V" tiene un carácter fenoménico y, por tanto, puede ser objeto de investigación empírica. En ese sentido, importa idealizar un método, un modelo para su medición, evaluación y predicción. Este es, ciertamente, el objetivo de nuestra investigación.

\section{CONCLUSIÓN}

Como resultado dela presente investigación podemos concluir que el vocablo "Conciencia" no es exactamente un concepto jurídico, mas tampoco es exclusivo de otras ciencias.

La palabra "Conciencia" (concientizar) es usada indistintamente en varios discursos jurídicos y dispositivos normativos que pertenecen a la filosofía moral, a la psicología y también al derecho. Esto se hace visible en las diferentes ramas y legislaciones jurídica donde se usan tales denominaciones: "conciencia ambiental", conciencia del consumidor, etc.

Así, debido a su especificidad y utilidad, tales construcciones lingüísticas, objeto de la presente etapa de investigación, es importante entender la relaciona del respeto y la obediencia de la ley por medio de la conciencia. En este sentido, podemos afirmar que la eficacia del derecho está condicionada al nivel de conciencia de los destinatarios de las normas. Esto debe ser considerado como una condición de todos los intercursos pacíficos entre hombre y hombre. La honra cívica se aplica igualmente a todos, sin excepción de clases. Luego, más allá de la significación, ciertamente, las causas del actual estado de conciencia o la falta de conciencia, no siempre fue objeto de preocupación o de estudios por parte de los juristas e investigadores históricos ni modernos.

Así, a los efectos del presente estudio, significamos la conciencia como el "Bieninterior", un estado espiritual que domina y define sentimientos, emociones, convicciones y actitudes, una condición que decide la resolución de dilemas morales. Por tanto, la conciencia es el eslabón que conecta el mundo del ser al mundo del deber ser y su edificación presupone un modelo jurídico-educacional que permita la "internalización” de los valores, esto es, del sentido de las normas morales y jurídicas. De esta manera, la conciencia puede ser edificada y reorientada con el auxilio de esos recursos. 


\section{REFERENCIAS}

ARISTÓTELES. Ética a Nicómacos. Trad. de Mário da Gama Kury. 2. ed.Brasília: Universidade de Brasília, 1992. Libro VI, cap. 7.

BITTAR, Eduardo Carlos Bianca. Curso de Filosofia do Direito. 7. ed. São Paulo: Atlas, 2009.

GONZÁLEZ Pérez, Jesús. Administración pública y moral. España, Madrid: Civitas, 1995.

HABERMAS, Jürgen. A Constelación Pós-Nacional. São Paulo: LitteraMundi, 2001.

ASTRAÍN, Ricardo Salas. Conciencia moral. In: TEALDI, Juan Carlos. Diccionario latinoamericano de bioética. Bogotá: UNESCO - Red Latinoamericana y del Caribe de Bioética: Universidad Nacional de Colombia, 2008.

LYCAN, William G. Filosofia da mente. In BUNNIN, Nicholas e E.P. Tsui-James (orgs).Compêndio de Filosofia. São Paulo: Loyola, 2002.

PIAGET, Jean. O juízo moral na niño. Trad.ElzonLenardon. São Paulo: Summus, 1994.

ROSS, Alf. Direito e Justicia. Trad. Edson Bini. Bauru, S P: EDIPRO, 2000.

SCHOPEÑAUER, Arthur. A sabedoria da vida. Trad. Jeanne Rangel. São Paulo: Golden Book, 2007.

WILLIAMS, Bernard. Moral: uma introdução à ética. Trad. Remo MannarinoFijo; revisão da tradução Marcelo Brandão Cipolla. São Paulo: Martins Fuentes, 2005. 